\title{
Providing Quality Online Education for Continuing Education
}

\author{
Xuelian Wu, Ying Liu, Yingjie Zhang, and Lili Ji
}

\begin{abstract}
Providing quality online education involve a systematic approach, and course design, instruction and interaction are vital parts. This paper reviewed students' learning process and ADDIE design framework and practices on course design, for us new comers, we need to realize its function and pay special attention to evaluation, that is neglected and important for us to improve.Instruction should base on sound pedagogical principle, WICHE's good practice can help instructors to refine their teaching strategies. Teachers should encourage student-teacher and student-student interactions, some culture aspects may impact or hinder instruction and interaction.
\end{abstract}

Index Terms-Course design, culture, instruction, interactions, online education.

\section{INTRODUCTION}

From 1960s, lifelong learning began to gain momentum. Many believe it is originated from [1]. Reference [2] traced its origin back to [3]. However [1] definitely attracted the world attention, lifelong learning has been intensively researched and has been put into practice. The audiences of lifelong learning are those already past their formal school years who wish to improve themselves, most of whom taken education part time or by distance. Modern technologies, especially the development of internet and web technology, make knowledge delivery ever easier, and universities, backed by its traditional educational resources, have been on the frontline of this paradigm shift trend.

The situation is similar in China. However, Online education is limited in both quality and scope, and the scope is limited by educational polices. In 2013, the government lifted its restrictions on online education, before those universities need permission to provide online educationfrom Ministry of Education and only 68 institutions obtained that permission. The main reason for doing that is quality concern, whether the reason is legitimate is not the discussion of this paper. However, we do believe the Ministry of Education should focus on quality control instead of limiting the

Manuscript received June 19, 2014; revised October 8, 2014.This work is supported by Undergraduate Education - Educational Reform Project and Research (municipal level) PXM2014_014224_000088 (Educational Reform of School of Continuing Education).

Xuelian Wu and Ying Liu are with School of Continuing Education, Beijing Information Science \& Technology University, Beijing, China (e-mail: 1276837443@qq.com, joyceliu515@hotmail.com).

Yingjie Zhang is with School of Public Management and Media, Beijing Information Science \& Technology University, Beijing, China (e-mail: 494775317@qq.com).

Lili Ji is with School of Continuing Education, Beijing Information Science and Technology University, Beijing, China (e-mail: 13693376661@139.com).
scope.Since all the universities are qualified for providing full time degree programs, why eliminate them from providing online education.

There are various kinds of adult higher education available in China, although they are carried out in variousforms in practice, it can be categorized into two categories, i.e. diploma programs and non-diploma training. Diploma programs includes self-studying programs and part time programs which offered by various institutions, including continuing education schools of universities, farmer's colleges, open universities, correspondence teaching colleges, and institutions for employees of certain industry or companies[4]. Self-studying programs differ from the rest in the finally exams, which is carried out on national level and therefore widely recognized, but the graduation rates is low. The borderline of above mentioned institutions has blurred, the open universities of China and the permitted continuing education schools offer similar programs and adopt similar online teaching methods. All the institutions have facilitated lifelong learning in different times. Now the online education, known for its conveniences and flexibility, has replaced correspondence and TV programs and become the main delivery method of distance education.

The deregulation provides an opportunity for those who are prohibited from offering online courses. Continuing education schools, most of whose perspective students have careers and domestic responsibilities and many of them either take education part-time or by distance, have an urgent need to adopt this new delivery method. However, online classroom differs from traditional classroom in many aspects. New opportunity comes with new challenges, they face formidable competitors. These permitted 68 universities include the most prestigious universities in the country. They have more resources, better reputation and a head start. All these factors require us to equip ourselves before we rush to the field.

The purposes of this paper are twofold. The first is to shorten our learning curve, and the other is that it may benefit those who are in similar situation like us. This is done by combining the reviews of theories and successful practices in the field with some unique Chinese aspects. In addition, we hope to raise the awareness of the importance of online education. We believe that quality education should be open to everyone who wishes to undertake it.As the British Open University's 2013 annual report put it:

"The OU's great achievement was to make higher education open to people without qualifications, and to make it accessible to people with different abilities. That was a huge achievement."1

1 See the Open University annual report 2012/13, at: http://www.open.ac.uk/about/main/mission/annual-reports. 
Online education is a feasible way to realize that goal.

\section{WAYS TO IMPROVE COURSE QUALITY}

Online learning is more than just put course materials online, it is a process to design a system, which requires experts of different fields. On this point, Reference [5] put it perfectly:

A distance education system should include the components of content, design, communications, interaction, learner environment, and management.

Accordingto [6], a successful course development team includes Subject Matter Expert (SME), graphic designer, web developer, programmer, and instructional designer.

These two systems mentioned above are functions of distance education system and their corresponding implementers.

Our discussions will be based on the two frameworks mentions above. Graphic designers, web developers and programmers are essential to ensure smooth delivery of the courses. However, our main focus is on how to design quality courses, we focus on mainly on the SME and instructional designer role.

We will base our structure on these aspects and divide our discussions into three categories, course design, instructions, and interactions.

\section{A. Course Design}

To design quality courses, two vital parties must work together closely, they are the SME and instruction designer.

\section{1) Subject matter expert (SME)}

According to [5], the main responsibility of the SME is to ensure that the course material are relevant, SME is responsible of designing exercises, activities and examination questions, to identify or create textbooks, to coordinate with instruction designer with copyright issues.

High quality SMEs are the guarantee of quality courses. However, some institutions don't possess necessary SME in house. One way to solve this is to seek outside help. A good example is the Open University of Hong Kong (OUHK), she has many courses designed by experts from all the other universities in Hong Kong, and many other top universities worldwide.

\section{2) Instruction designer}

Instruction designer are vital part of the team, which is largely neglected in my university and many others we are familiar with, there is no clear boundaries between SMEs and Instruction Designers. Therefore we elaborate more on this subject. Reference [7] describes the ADDIE functions of Instruction designer as follows:

- Analysis - the process of defining what is to be learned.

- Design - the process of specifying how learning will occur.

- Development - the process of authoring and producing thematerials.

- Implementation - the process of installing the instruction in the real world.

- Evaluation - the process of determining the impact of instruction [6].
Instruction designers need to help SMEs with pedagogicalstrategies and options [6]. To fulfill this role, the instruction designers need knowledge about student's learning process. Basically there are three schools of learning, i.e. behaviorist, cognitivist and most recently constructivist. According to Stanford Encyclopedia of Philosophy, abehaviorist approach demands behavior evidence to evaluate the learning outcome, the learner's state of mind is irrelevant. Cognitive approach sees learning asan internal process, it involves memory, motivation and thinking [8]. The constructivist argues that individual experience influences the outcome, which is the result of interaction between personal experiencesand information.

These three schools are all used to design online course contents, the behaviorist approach fits well to teach what, cognitivist approach can be used to teach how, and constructivist fits well to teach why, it involves high level thinking [8].

The course design should be based mostly on the behaviorist and cognitive schools of learning. In the same article, Reference [8] also suggests some of the practical suggestions for course design, some are particularly suitable for our students, and they are:

- Learning material should be designed sequentially.

- Learners should receive feedback regularly which they can realize how they are doing with the courses.

- Place important information in the center of the screen.

- Highlight the important criterion to attract learner's attention.

- Appropriate material match students cognitive level.

- Provide frame-work models to build a big picture of the course and they can use to retrieve the detail of the course.

- Use pre-instructional questions to set expectations, to help learners recall previous knowledge, and to motivatelearner to find additional materials.

- Online learning should be presented between five to nine items to help learner transfer information from short-term memory to long-term memory.

Meanwhile, Reference [9] provided some useful advices in the same book after reviewing [10] and [11]. Abstract ideas are better understood if they are organized in a meaningful way; comparison and contrast, similarity and grouping can aid perception and recall; presentations focus on differences are perceived better by learners.

These suggestions are built upon sound theories, and also they are based on many years' research and practice.Before designing a course, the designers needs to have a systematic approach in mind. During the implementation phase, the designers need to make sure that each procedure has been implemented efficiently. This is very obvious, but in practice, some of the functions are easily overlooked. We find evaluation is particularly weak in my school, although student survey is carried out after each course; the result has not been treated seriously. It is rather a formality than a way to improve teaching. We need to reflect not only on survey result, but also the problem we encounter during the process, which is especially important at the beginning. The other aspect is that we need to provide more comprehensive course framework than we do in the traditional classroom, in which instructors can answer student's questions on site, while that 
is not the case for online instruction. Reference [12] shows that Chinese students display a strong need clearly structured courses, where the logic should be made transparent to students.A comprehensive framework does not always equal the structure of the textbook, the connections of different part and additional knowledge should be included. Therefore a comprehensive framework is more important for Chinese learners.

\section{B. Instruction and Feedback}

\section{1) Instruction}

The good practice of instructions should base on sound principles, Reference [6] reviewed the American Association of Higher Education's "Sevenprinciples for good practice in undergraduate education" and Western Interstate Commission for Higher Education (WICHE)'s "Principles of Good Practicefor Electronically Offered Academic Degree and CertificatePrograms". They both are sound principle and some of them are similar. We will use later as an example because they are specially designed for the online learning environment, they are as followings:

- Programs provide for timely and appropriate interaction between students and faculty and among students.

- The institution's faculty assumes responsibility for and exercisesoversight over distance education, ensuring both the rigor ofprograms and the quality of instruction.

- The institution provides appropriate faculty support servicesspecifically related to distance education.

- The institution provides appropriate training for faculty whoteach in distance education programs.

- The institution ensures that students have access to and caneffectively use appropriate library resources.

- The institution provides adequate access to the range of studentservices appropriate to support the programs, includingadmissions, financial aid, academic advising, and delivery of coursematerials, and placement and counseling [13].

These principle set guides for institutions to set up their mission, it is also useful for faculty to refine their teaching strategies. However, implementing all principles mentioned above requires considerable financial resources. Most continuing education colleges in Chinese universities are underfunded and understaffed. They are regarded as non-core part of the institutions, andmost teachers are hired from other departments or from other universities. Tsinghua University, the first universities permitted to provide online education, has stopped offering online degree programs since 2004, their main focus has shifted to high level trainings, the continuing education colleges has become the money making unit. Theopen universities of China, institutions solely focus on adult education, has to form an alliance with other universities to provide teaching staff. The continuing education school which we worked for has recently transferred all the teaching staff to other departments, all the future teaching will rely on part-time teachers.

This approach can keep costs down. However, institutions need to manage its shortcomings. For instance, instabilities, frequently changing faculty will affect the consistence and quality of course. Most of the hired faculty is from traditional classroom, if they apply the techniques of the traditional classroom directly to online teaching, the result will be compromised. Therefore, the faculty needs to be trained to teach effectively, relying heavily on part-time faculty makes adequate training difficult.

Institutions can't wait for the change of policy and more budget allocation, if they aspire to provide quality courses; they have to operate under the current financial resources. Fortunately there are various successful cases managing part-time faculty with satisfactory results. The most extreme and most successful case would be University of Phoenix online (UOP), which is accredited by North Central Association of Colleges and Schools since 1978. Some of the strategies UOP employed are:

- They use exclusively part-time teachers and teachers' sole responsibility is to teach (there is no research, course creation, student service, management, et al.).

- UOP offers few student supports; the library is only accessible online.

- University doesn't provide officesfor teachers.[14]

UOP estimates they need to spend 100 hours on the first course, less as they gain experiences; UOP not only doesn't receive government funds, it has consistently returned profits to its shareholder; UOP adopt a business approach instead of an academic approach, it is one of few profitable for-profit universities in the U.S. [14].

UOP provide quality courses with limited budget, it sets a perfect example for Chinese universities. If the teachers are relieved of course creations, the responsibilities automatic falls back on the universities, this willminimize the impact of unstable teaching staff, the course provided will be consistent and can be tailor-designed for online teaching.

As for training, Reference [6] provides a very good method, for on-line teachers to be adequate, they first need to be on-line learner, and they should enroll in an on-line course that teaches how to develop online instructions. This will be an effective way to train teacher.

Part-time teachers can achieve satisfactory result, but appropriate management is the key to achieve the goal. Faculty need to set its standards for teaching and provide appropriate support for faculty and students. Meanwhile, faculty should realize the differences between the traditional classroom and online classroom. Institutions need to find a balance between training faculty and retaining the skilled.

\section{2) Feedback}

Feedbacks help students better organize their learning schedules and keep them motivated. Appropriate feedbacks enable students to monitor their learning progresses.Reference [9] summarizes the principles of giving feedback as follows:

- The more mature the learners are, the more informal the feedback should be.

- For more mature learner, the correct answers should be just marked correct.

- Feedbacks needs not be immediate, but the learners should be informed when to expect them.

- Feedbacks should be in appropriate order, especially for complex tasks.

- Feedback can be reduced when the learners become more mature. 
Feedback is always associated with assessments, it mainly comes from instructor. Broadly speaking, feedback also includes peer feedback, for instance, students post their comments on online discussion forum. Both teachers'feedbackand peers' are valuable, but students might perceive them differently. Studies show that students from China often view teacher as an authoritative figure, they value teachers' feedback more than peers' [14].

\section{Interaction}

Nowadays, with the rising popularity of constructivist theory, interaction attracts both educators' and instructors' attention. The first rule of both "Seven principles for good practice in undergraduate education" and WICHE's principles emphasize on interactions. Reference [15] discussed student-student, student-teacher and student-content interactions. Teacher-teacher, teacher-content and content-content interactions were added by [16]. All the interactions mentioned above are important to ensure quality of online learning. Teacher-teacher interaction can improve teachers' skills by communicating with colleagues; teacher-content interaction can keep the contents up-to-date and improve the perceptibility of contents to students; content-contentinteraction is a newly developed concept that the contents are programmed that theyare automatically connected with some real-time sources [17]. In this paper, we focus our discussion on the three principles first presented by Moore. Student-content interaction includes two components, how the contentsare designed and presented.This is already included in our course design. We will focus our discussion on the student-student and student-teacher interactions. The interaction in traditional classroom is mostly taken in synchronous form, whereas interaction in online learningis in asynchronous form except online conferencing. If too much asynchronous interactionsscheduled in online environment, the flexibility will be reduced, and the advantage of online education will be diminishing. Therefore most of the interactions should be in asynchronous nature.

Interaction, affected by various factors, is a weak point in Chinese online education.We identify the class size and the culture as important ones. If a class is too large, effective interactions will be difficult, especially student-teacher interaction.It is very difficult for teachers to handle the large amount of communications. Interactions also affected by culture, in this article, we do not need to deal with the multi-culture issue, but some aspects regarding Chinese culture will shed light on how to make interaction effective.

Student-teacher interaction is integral part of education regardless the forms, either in classroom or on the web. The benefits of more student-teacher interactions include helpingstudents better understand the contents, guide and motivate students to find relevant information, stimulate deeper-level thinking.

Student-Student interaction is the result of the rising popularity of constructivist theory. Reference [17] point out:

Modern constructivist theorists stress the value of peer-to-peerinteraction in investigating and developingmultipleperspectives.

In Chinese online learning education, student-student interaction is even more lacking than student-teacher interaction. It is largely neglected because of the institutions' and teachers' negligence.

There are many advantages to implement peer-to-peer interaction. Interaction can help studenttransform lecture contents to personal knowledge. In a large class, a successfully executed student-student interaction can also reduce teachers' burden.

Despite the advantages, peer interaction should be implemented with caution. First institutions need to prepare teachers and tutors with the transforming role from instructors to facilitators. Meanwhile, there are some culture issues affecting students' behavior need to considered, Reference [14] review provides some useful suggestions:

- In highuncertainty avoidance culture; students need highly structured course, the rules should setup in advance what they are expected to do.

- Chinese culture tradition discourage the "nail that sticks up", some students tend to be passive on online discussion.

- Asian student value instructors' advice more than peers', they tend to get frustrated when they teacher is not presented during the discussion.

These culture studies mostly based on Asian students in another culture, some of the student might have language barriers that prevent them from participating in online environment, while the situation might be improved when they discuss in their mother tone. However, these aspects remains relevant when we conduct our online discussion activities, for instance, setting up clear goals and rules what students are expect to accomplish. Reference [14] review presents [18] suggestions for instructors:

- Get to know students. Encourage students to send their pictures and post their background information and interests online.

- Encourage students to communicate with each other both online and offline. For example, exchange phone numbers, meet in person, use email, fax, the discussion boardand the chat room.

- Encourage face-to-face interactions or meetings with classmates and instructors when possible.

These suggestions are not confined to a particular culture, Reference [19] conducts an online education case study, and it shows that even learners from low uncertainty avoidance culture needs the encouragement from teacher to weekly topic to more deep discussion. It might be more difficult for Chinese instructors to conduct a successful online learning community; therefore the instructors need to be prepared mentally to face the challenges.

\section{CONClusions AND REFLECTIONS}

Although there are many theories and successfully cases on online education, there is no universal formula that guarantees success. Theories and empirical studies provide frameworks and guidelines, which help institutions and educators to steepen their learning curves. However, providing online education is still a trial and an error process for both institutions and faculty.

For these newcomers like our institution to provide successful online education there is some essential aspects 
command attention.

Before providing, there must be appropriate fund secured, the universities should include online education as part of their long term strategy. Online education and continuing education are a good match.

To design qualities courses, ADDIE model provides a valuable framework, especially the evaluation function, which provides important information for improving since we are new to the field. The practical advices such as providing comprehensive frameworks and using pre-instructions to enhance students' learning process.

Institutions must provide training for faculty members, after all online classroom is not identical with traditional classroom. Training can be in various forms, but one particular useful is to have faculty to take online learning courses about how to teach online.

Encourage student-teacher and student-student interactions. These interactions can help students consolidate knowledge and develop reflective thinking abilities, in addition improve their team working skills, which is crucial and otherwise lacking in online courses.

Keep class in a reasonable size. Too large a class might overwhelm teachers and reduce the quality of interaction.

Most studies this paper referred are not based on Chinese market, there are two reasons. One is that these studies are more thorough and systematic compared with Chinese studies, they provide fundamental principles that can be generalized. Another is that online education is more mature in these counties where the studies carried out than in China, Basically any universities can carry out online education if they choose to as long as they comply with regulations. Contrarily there are only 68 universities in China that are permitted to provide online education before 2013, and many universities treat online education as a side function. Education is a practical science, experience comes with practice. Therefore these institutions have valuable experiences that can help us to improve.

More researches on education in China should focus on online education. Empirical studies can help teachers improve their teaching skills and ultimately benefit the learners.

\section{REFERENCES}

[1] E. Faure, Learning to Be, Paris: UNESCO, 1972.

[2] J. H. Knoll, "Lifelong learning - A new termfor an old idea? The search for historical roots," Odgojneznanosti, vol. 11, 2009, pp. 103-118.

[3] C. O. Houle, The Inquiring Mind. Madison, The University of Wisconsin Press, 1961.

[4] Z. M. Wu, "Will the adult education in China end: The crises and challenges faced in the new period," Open Education Research, vol. 19, no. 4, Aug. 2013.

[5] G. Moore and G. Kearsley, Distance Education: A Systems View, Wadsworth Publishing Company, 1996.

[6] D. Caplan, "The development of online courses," Theory and Practice of Online Learning, Athabasca University, 2004, ch. 7.

[7] B. Seels and Z. Glasgow, Making Instructional Design Decisions, (2nd ed.), Upper Saddle River, NJ: Merrill, 1998.

[8] M. Ally, "Foundations of educational theoryfor online learning," Theory and Practice of Online Learning, Athabasca University, 2004, ch. 1 .
[9] P. J. Fahy, "Media characteristics andonline learning technology," Theory and Practice of Online Learning, Athabasca University, 2004, ch. 7.

[10] P. Bourdieu, Distinction: A Social Critique of the Judgmentof Taste, Cambridge: Harvard University Press, 1984.

[11] M. Fleming, "Displays and communication," in R. M. Gagne (Ed.), Instructional Technology Foundations, Athabasca University, 2004, ch. 7, pp. 233-260.

[12] P. J. Smith and S. N. Smith, "Differences between Chinese and Australian students: Someimplications for distance educators," Distance Education, vol. 20, no. 1, pp. 64-80, 1999.

[13] G. B. Jackson, "University of Phoenix: A new model for tertiary education in developing countries?" TechKnowLogia, vol. 2, no. 1, pp. 34-37, January/February, 2000.

[14] S. Uzuner, "Questions of culture in distance learning: A research review," International Review of Research in Open and Distance Learning, vol. 10, no. 3, 2009.

[15] G. Moore, "Three types of interaction," the American Journal of Distance Education, vol. 3, no. 2, pp. 1-6, 1989.

[16] T. Anderson and D. R. Garrison," Learning in a networkedworld: New roles and responsibilities," in C. Gibson (Ed.), Distance Learners in Higher Education, Madison, WI: Atwood Publishing, 1998, pp. 97-112.

[17] T. Anderson, "Toward a theory of online learning," Theory and Practice of Online Learning, Athabasca University, 2004, ch. 2.

[18] L. Thompson and H. Ku, "Chinese graduate students experiences and attitudes towardonline learning," Educational Media International, vol. 42, no. 1, pp. 33-47, 2005.

[19] M. Dorit, "The teacher's role in developing interaction and reflection in an online learning community," Educational Media International, vol. 40, no. 1,2003 .

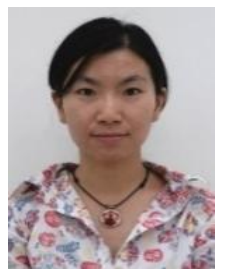

Xuelian Wu was born in Hubei Province, China in July 1978, who completed her bachelor's degree in literature in Art Department, Minzu University of China in 1999 and completed her master's degree in literature in Chinese Painting Department, China Central Academy of FineArts in Beijing in 2005. She is a lecturer now in Beijing Information Science \& Technology University in Beijing, who has been working there since 1999.

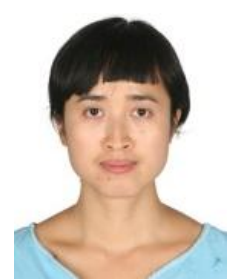

Ying Liu was born in Yibin, China on 15th May 1975, who completed her bachelor's degree in art history, China Central Academy of Fine Arts in 1998 and completed her master's degree in art history, Central Academy of Fine Arts in 2003. She has been a lecturer in Beijing Information Science and Technology University since 2003.

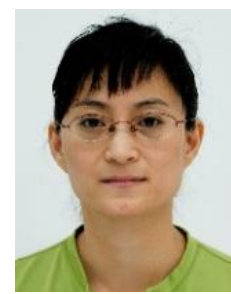

Yingiie Zhang was born in Hebei province, China in September 1970, who completed her bachelor's degree in arts and crafts decoration in Beijing Institute of Fashion Technology in 1993. She has been working in Beijing Information Science and Technology University since 1993 and she is an associate professor there now. In recent years, she has published 10 extra articles and compiled 2 books.

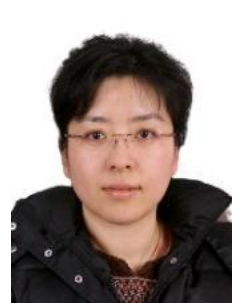

Lili Ji was born in Dongtai, Jiangsu Province, China, in Oct. 1974, and graduated from Minzu University of China with the master degree 2004. She is an assistant professor, who has been working in School of Continuing Education at the Beijing Information Science \& Technology University (BISTU) since July, 1994. Her teaching interests are in the fields of computer science. Currently her research focuses on adult education and teaching management. She has published over 10 academic articles and one book. 